Literatura y Lingüística $\mathrm{N}^{\circ} 26$

ISSN 0716-5811 / pp. 101-113

\title{
Cuerpos agónicos: representaciones de la muerte en tres poetas chilenos
}

\author{
Paula Isabel Tesche Roa* \\ Noemí Pamela Sancho Cruz**
}

\section{Resumen}

Este artículo analiza la experiencia de la agonía y las representaciones de la muerte en los hablantes de los poetas Jorge Torres en su texto Poemas Renales, Enrique Lihn en Diario de Muerte y Gonzalo Millán en Veneno de Escorpión Azul. Los análisis consideran los aportes del psicoanálisis y la semiótica literaria. La teoría psicoanalítica privilegia la comprensión del sujeto del texto, así como la interpretación de los significantes y significados ligados a las representaciones. Las reflexiones del hablante poético tienen un carácter testimonial, lo que permite una amplitud semiótica y evidencia una complejidad en los proyectos escriturales. Los textos escogidos nos convocan desde la poesía a repensar una experiencia tan intensa como la proximidad de la muerte entendida como límite y como revalorización de la vida.

Palabras clave: enfermedad, muerte, Jorge Torres, Enrique Lihn, Gonzalo Millán.

\section{Agonising bodies: representations of death in three Chilean poets}

\begin{abstract}
This paper discusses the experience of agony and death representations in the poetic voice of Jorge Torres's Poemas Renales, Enrique Lihn's Diario de Muerte and Gonzalo Millán's Veneno de Escorpión Azul. The analysis considers the contributions of psychoanalysis and literary semiotics. Psychoanalytic theory privileges the understanding of the subject of the text, and the interpretation of the signifiers and meanings linked to the representations. The poetic voice reflections have a testimonial character that allows a greater semiotic range and presents complexity scriptural projects. The selected texts from the poetry bring us together to rethink such an intense experience as the proximity of death understood as a limit and as appreciation of life.
\end{abstract}

Key words: illness, death, Jorge Torres, Enrique Lihn, Gonzalo Millán.

Recibido: 20-06-2012 Aceptado: 09-07-2012

* Doctor @ Ciencias Humanas. Universidad Austral de Chile. paulatesche@yahoo.com

** Magíster Literatura Hispanoamericana Contemporánea (UACH). Pontificia Universidad Católica de Chile.Chile.npsancho@puc.cl 
Cuerpos agónicos: representaciones de la muerte en tres poetas chilenos / Paula Tesche, Noemí Sancho

\section{Introducción}

Al decir de Susan Sontag (1989), la enfermedad está teñida por "fantasías punitivas o sentimentales" propias de la cultura occidental que configuran estereotipos acerca del padecimiento de una enfermedad crónica o terminal, tales como el incapacitado o inválido. Señala también que estos estereotipos funcionan como siniestras metáforas que aprisionan al sujeto. El problema del estereotipo es que genera una identificación de carácter simplista y burda que no promueve la reflexión del sujeto, sino que lo liga de manera rígida ante los discursos sociales.

Hemos elegido abordar el padecer que ocasiona la enfermedad desde textos literarios, porque éstos presentan metáforas ante la agonía que cuestionan los estereotipos culturales; como el del enfermo sin voz que es objeto de su malestar (Sontag, 1989). Entendemos por metáforas la creación de imágenes literarias ante la enfermedad (Sontag 1989) que se configuran mediante la interpretación, en el texto, de experiencias y que permiten el surgimiento de un nuevo sujeto (Kristeva, 1994). Estas metáforas tienen por contexto la creación literaria que, mediante ritmos, signos y formas permiten al mismo tiempo, testimoniar el afecto, transmitirlo al lector como una realidad presente y, en ese acto, dominarlo o vencerlo (Kristeva, 1997). De esta manera, la identificación del sujeto con las imágenes trasciende la catarsis, constituyendo una forma de inscribir la vivencia de la proximidad de la muerte como un duelo; el que comprende los procesos de representar la pérdida de la vida y mediante el texto hacer del sufrimiento un acto social.

Por otra parte, en este estudio nos interesa realizar una conexión interdisciplinaria entre el psicoanálisis y la semiótica literaria. Considerando que la vivencia del cuerpo agónico, que oscila entre lo vital y lo mortal, se presenta en un texto literario no sólo como signo de un padecimiento sino como una re - significación subjetiva, que obliga a valorar la relación entre la escritura y el sujeto. El cuerpo textual adquiere diversos matices semánticos como la transgresión; habla de una experiencia límite, y, a la vez, permite mediante la creación literaria configurar nuevos sentidos de la corporalidad que regulen la dimensión excesiva de la agonía. La noción de cuerpo agónico la entendemos en su significado etimológico, tanto en latín, es decir como "angustia que precede a la muerte" como en griego, esto es como "oposición, competencia" (Gómez de Silva, 2006: 38). En el texto literario, la agonía reúne vida y muerte porque el sujeto presenta la angustia ante la muerte pero también una lucha, una forma de competir por la vida. La presencia de la muerte y la apetencia

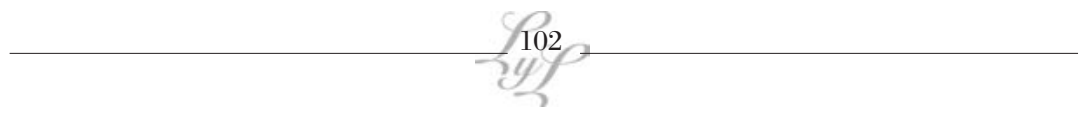


desenfrenada por la vida, se presentan como transgresión al ser relativas al exceso. Desde Michel Foucault "la transgresión es un gesto que concierne al límite; ahí es donde, en la delgadez de esa línea, se manifiesta el resplandor de su paso, y tal vez también su trayectoria en su totalidad, su origen mismo" (1999: 167). La trasgresión desafía los límites hasta los extremos y requiere del límite para desafiarlo hasta el borde.

Presentaremos este problema desde un breve análisis de los textos Poemas Renales de Jorge Torres (1992), Diario de Muerte de Enrique Lihn (1989) y Veneno de escorpión azul de Gonzalo Millán (2007). Estos textos tienen el valor de representar un testimonio y una creación literaria cuyo aporte es problematizar y reconfigurar la tensa relación del sujeto al cuerpo agónico o enfrentado a la muerte.

En la producción poética de Jorge Torres la poesía es un soporte que permite un amparo ante la realidad y trascender hacia otra dimensión de la existencia; por otra parte, en el proyecto escritural de Lihn, la poesía surge como una necesidad imperiosa, como un mandato de sobrevivencia, en un momento de tan profundo menoscabo del yo, como lo son los últimos días de vida. Finalmente, en el texto de Millán tanto su relato biográfico como sus poemas se presentan como un mecanismo de sobrevivencia; la escritura es la forma que tiene el autor de luchar por su vida.

Como señalamos, estos textos construyen nuevas metáforas ante el padecimiento y constituyen comunicaciones públicas de una enfermedad crónica y de la muerte y, en este sentido, son textos transgresores. No es frecuente hablar de imaginar la proximidad a la muerte. Desde el psicoanálisis, las palabras más comunes para caracterizar a la muerte son ominoso y tabú. Según S. Freud (1919), ominoso es una palabra que se reduce a dos significados que sin ser opuestos, son ambivalentes: lo familiar o agradable y lo clandestino o que se mantiene oculto. Sería todo aquello que destinado a permanecer en secreto ha salido a la luz. Las enfermedades crónicas y la proximidad de la muerte responden a lo ominoso, dado que, aunque (al sujeto) resultan desde siempre familiares (a pesar que) producen incertidumbre y se mantienen en lo clandestino. Por otra parte, la muerte puede entenderse como un tabú. En el origen de la significación de la palabra también se encontrarían dos acepciones. Por una parte, lo sagrado y, por otra, lo peligroso, prohibido o impuro (Freud, 1913). Lo particular del tabú es que es algo prohibido por sí mismo, que carece de explicación, es de origen desconocido e incomprensible y siempre parece natural a quienes se someten a él. 
Lo transgresor de los textos a analizar es que se arriesgan a crear significaciones ante la enfermedad y la muerte y ensayan una respuesta ante estas vivencias entendidas como palabras cuyas significaciones se aproximan a lo tabú y ominoso.

\section{Poemas renales de Jorge Torres}

Comenzaremos con un breve análisis del texto Poemas Renales de Jorge Torres publicado en 1992, del que se ha efectuado un extenso y riguroso análisis crítico en el libro En libre plática editado por Sergio Mansilla y publicado en 1994. Por este libro, sabemos que Torres se encontraba afectado de una enfermedad renal que lo obligaba a realizarse procesos de diálisis, de ahí el nombre del texto, que introduce el cuerpo y particularmente la enfermedad del órgano del riñón como el que motiva la escritura. Es decir, el órgano funciona como una sinécdoque de la enfermedad que condensa toda la significación de lo mórbido.

Nuestra hipótesis consiste en interpretar la poesía del autor donde el dolor corporal le permite al hablante orientarse hacia lo trascendente, no en el sentido de convocar la presencia de lo teológico o metafísico como un bien supremo, sino que la voz poética encuentra en el desafío y soporte de la ley del padre un amparo. Entendemos la noción ley del padre, en el sentido que es propuesta por S. Freud en su texto "Totem y tabú" (1913). Es decir, el padre representa un poder porque está identificado con una ley que se traduce en lo psíquico como un mensaje ambivalente, a saber, todo hijo debe ser como el padre, pero le está prohibido ocupar su lugar y ejercer los derechos que él tiene.

En el texto podemos asistir a diversas representaciones del hablante ligadas a lo religioso. El sujeto se identifica con un penitente, estableciendo relaciones intertextuales con el sufrimiento de Cristo. Sin embargo, vemos que la relación con Dios no comprende una experiencia permanente ni protectora. Así, en el poema "Tuve a Dios", el sujeto enuncia: "Tuve a Dios en mis manos/de ambas/manco he quedado./Entre ceja y ceja, lo tuve/ bizco/ estoy desde entonces" (Torres, 1992: 19).

Más bien la experiencia del dolor no se aleja de las dimensiones del cuerpo, del malestar físico y si bien puede, tal como señala el hablante, producir "ataques de mudez" o "cierta lentitud al hablar", no interrumpe la queja. Incluso podríamos decir, que la enunciación se centra en los fluidos corporales, el sudor, las sales y minerales del soma y sobre todo

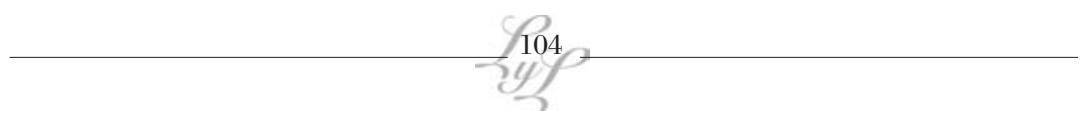


en la sangre. Vemos que la sangre se depura, se somete a los intervalos de sístole y diástole, se vacía y fluye.

El cuerpo afectado por un padecimiento de la sangre, una enfermedad renal, lleva al hablante a interrogarse por sus filiaciones, aquello que ha sido heredado, transmitido por la vía paterna. No es casual que el libro esté dedicado al padre y que éste se encuentre ausente, tal vez, por una enfermedad semejante, pues el hablante nos presenta un poema centrado en la figura del "padre moribundo" que llega desde el "desangradero".

Así como la relación con Dios que también es un padre, pero simbólico, es conflictiva, también lo son los afectos que se desatan con este padre moribundo. En el poema titulado "Delito de aflicción con pena de muerte" encontramos los siguientes versos: "Sólo besar su frente puedo, digo/ inhibiendo el inmenso y necesario gesto/ ahora impedido de consumarse en un abrazo,/ padre/ un simple y necesario abrazo,/ padre,/ tan sólo un abrazo,/ padre./ No obstante, no siendo yo/ ni cercanamente el hijo de Dios,/ ni tú remotamente Dios mismísimo/ padre/ reclamo ahora/ airado/ tu abandono" (Torres, 1992: 35). Padre e hijo se encuentran a propósito de la muerte. Esta no es sólo la que restringe la proyección de la existencia en el tiempo, sino la que motiva al hablante poético. Como enuncia en el poema "La muerte ensayada" donde afirma en alusión a la muerte: "Pez en el agua es Usted en el silencio./ El mismo que habita tras las palabras cuando éstas callan/ Locuaz, charlatán, vocinglero soy por ello" (Torres, 1992:45). De esta manera, la proximidad de la muerte permite no sólo el desafío sino también la posibilidad de encuentro, a través de la poesía, con la vida.

En Libre Plática (1994), Oscar Galindo ya había destacado esta relación entre la muerte y la escritura, a propósito de un texto de Foucault donde éste reflexiona que, en los griegos, la escritura tenía por fin la inmortalidad y que ésta borra la singularidad del escritor. Pero lo que nos interesa destacar es, tal como afirma Galindo: "la escritura se convierte no en un modo de perpetuar la memoria del autor o de sus personajes en la palabra, sino en un modo de resistencia, digamos que el sujeto escribe para dar señales de vida" (Mansilla, 1994:88).

\section{Diario de muerte de Enrique Lihn}

Ahora nos centraremos en el libro Diario de Muerte de Enrique Lihn, sin realizar análisis de relaciones intertextuales ni considerar los textos previos del autor. Nuestro interés al escoger este libro se fundamenta en 
que fue publicado el año 1989, un año posterior a la muerte del autor. Representa, según Adriana Valdés y Pedro Lastra, quienes reunieron y trascribieron los textos, "una experiencia extrema en la literatura chilena" pues, por una parte, Diario de muerte se escribe entre el prematuro fin de la plenitud de la vida (Lihn tenía 59 años al morir) y la certeza de un cáncer terminal. Por otra parte, el texto presenta el esfuerzo de sobreponerse al derrumbe del cuerpo causado por la enfermedad sin oponerse a la muerte sino que crea un sentido poético para la muerte que se aproxima. De esta manera, en este cuerpo agónico, la muerte se encuentra y enfrenta en el texto.

Nuestra hipótesis consiste en pensar que la poesía de Lihn presenta la muerte como una zona de intenso deseo que obliga al hablante a construir una ley que regule al texto poético como cuerpo textual. La vivencia de la proximidad de la muerte se relaciona con un desborde de angustia en el hablante que si bien experimenta desear morir, también lo obliga a desear vivir y de esta forma regular, mediar o interceder por la vida.

Al hablar de la realidad de la muerte no sólo entendemos su presencia en la vida cotidiana del autor: la espera en la consulta por un diagnóstico, la visita de los médicos o los recuerdos de su cirujano; sino el enfrentamiento del sujeto del texto con el límite de la significación poética ante esta experiencia, asunto que es retratado desde los primeros versos del primer poema de Diario de Muerte, donde el sujeto enuncia: "Nada tiene que ver el dolor con el dolor/ nada tiene que ver la desesperación con la desesperación/ Las palabras que usamos para designar esas cosas están viciadas/ no hay nombres en la zona muda" (Lihn, 1989:13). En estos versos el hablante introduce el dolor y la desesperación como vivencias de máxima intensidad y denuncia aquello que llama "la zona muda" o "esa cosa muerta que existe en el lenguaje", que nos permiten entenderla como una zona imposible de nombrar o que pone un límite ante las posibilidades de la significación poética.

Desligarse del dolor y de la desesperación es tan imposible como renunciar a lo más humano o renunciar al yo, porque ambos estados le permiten al poeta construir un proyecto escritural. Es decir, Los únicos estados aliviadores que se presentan en el texto, ante el impacto de estas vivencias, son espacios representados como ciudades; como el sueño que es un espacio habitable donde existe, como señala el hablante, "una fracción de segundo" de alivio que reanima el cuerpo.

El tránsito entre diversas realidades, tiempos y países como el de los sanos y enfermos, es también una zona que mueve al sujeto hacia la

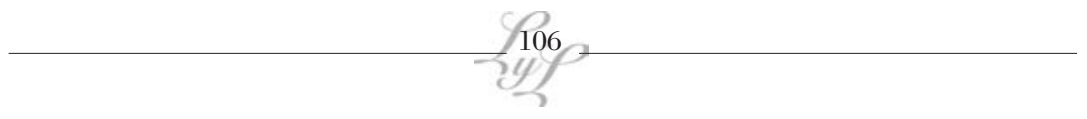


fragmentación. Así, se interroga: “¿Quién de todos en mí es el que tanto le teme a la muerte?" (Lihn, 1989:47).

La realidad de la muerte es entonces una pregunta por la multiplicidad de sujetos que padecen "hundidos en el duelo" y donde habita "un ciudadano de tercera llamado ego". Este yo fragmentado se identifica con la figura de la nada y el vacío. Sin embargo, el vacío no se presenta como falta de deseo sino como un excedente de palabras que, configurando un sinsentido, quebrantan la unidad del yo.

La unidad del yo ante la muerte no se fragmenta por efecto de la ausencia de vida o la falta de vitalidad. Lihn utiliza la figura del espejo para nombrar este quiebre del yo. En el poema "Casi cruzo la barrera" señala que la fragmentación no se corresponde con aquello que "no se puede ver", el espejo no copia la realidad de la desesperación, sino, al revés, "el espejo se llena, por fin, de su nada". Es una imagen saturada de muerte.

Otra forma de nombrar esta saturación es la que utiliza en el poema What's one, o sea, qué es uno, y que consiste en la repetición de estas palabras con un signo numérico en orden creciente en la parte superior. Veamos el poema:

\section{[What's one...]

$1 \quad 2 \quad 3$ \\ "What's one/ and one / and one/ and one/ and

$\begin{array}{llllll}4 & 5 & 6 & 7 & 8 & 9\end{array}$ \\ one/ and one/ and one/ and one/ and one/ and one?}

Estos son los graffiti de la muerte en la carne" (Lihn, 1989:44).

Se trata de marcas de la muerte de aquellos que hemos sido y que, como señala el hablante, constituyen, a la manera de un graffiti, fracturas del yo que llevan a representarlo como una mutación hacia lo inerte.

En el texto, el cuerpo ha pasado a ser representado como carne, materia inerte irrepresentable como una sombra, suciedad, desecho, el resto que deja una "bestia tufosa" y "devoradora" que es la muerte. La muerte se presenta en su dimensión material en el siguiente texto: "la muerte es justamente el protoplasma de este hijo/ sin madre/ nacido de mi muslo/ Esa mierda que nunca pude excretar/ aferrado a mí como el nódulo al pulmón/ cancerosamente diestro en la toma de poder (Lihn, 1989). La voz poética describe la muerte como una basura producida y perteneciente al cuerpo que no porta la vitalidad del nacimiento porque 
no logra circular entre los fluidos corporales, se estanca en una zona del cuerpo para reproducirse y expandirse en forma violenta. En Diario de muerte: "Ella es simplemente otro ser, y su conexión contigo una fisura aunque lo alumbres y te pudras para que sea" (Lihn, 1989:46).

Sin embargo, es en el poema "La ciudad del Yo" donde Lihn afirma que existe: "una desahuciada esperanza" "aferrada/ a la imitación de la vida". La imitación de la vida es aquello que parece ser vital pero es inerte como lo es una "mano artificial" título de un poema donde tal como la mano de un maniquí sólo tiene la forma de una mano real. En el texto: "mueve su mano ortopédica como un imbécil que jugara/ con una piedra o un pedazo de palo/ y el papel se llena de signos como un hueso de hormigas" (Lihn, 1989:43). El cuerpo, además de aparecer fragmentado e inerte, se presenta como un cuerpo textual que encarna lo desmedido y brutal de la muerte tanto para el sujeto como el autor.

Ante esta desmesura, podemos interrogarnos cuál es el fundamento de esta obra. Lihn señala que el cuerpo de la obra no tiene origen, fin, ni dueño y surge desde el deseo humano de volver a tejer las hebras desunidas de la historia y de crear un sentido ante el cuerpo del otro. El sentido de la poesía y en especial ante la muerte es el gesto urgente de reunir y volver a ligar palabras. Se trata de producir significaciones reguladas o legalizadas ante el exceso de lo mortal cuyo sentido textual está ligado a lo más humano que cada uno tiene. En el caso de Lihn esto es la poesía o, como el mismo señala: "déjenme acabarme en mi ley" (Lihn, 1989:59).

\section{Veneno de escorpión azul de Gonzalo Millán}

En el caso de Veneno de escorpión azul (2007) de Gonzalo Millán, asistimos al relato que antecede a la muerte del autor, provocada por un cáncer pulmonar en su fase terminal. Este texto es una compilación de las anotaciones del autor, fechadas por él, que fueron transcritas y editadas por María Inés Zaldívar, pareja del poeta.

La manera en que se ha titulado el texto se relaciona con el veneno que produce el rhopalurus junceus (conocido como escorpión azul) que se ha utilizado en Cuba como tratamiento alternativo para la cura del cáncer.

Este diario poético relata desde el momento en que el poeta conoce su situación hasta dos semanas antes de su muerte (hasta cuando le quedaron fuerzas para escribir). En este proceso, aparece la sustancia venenosa del escorpión como una esperanza para prolongar su vida.

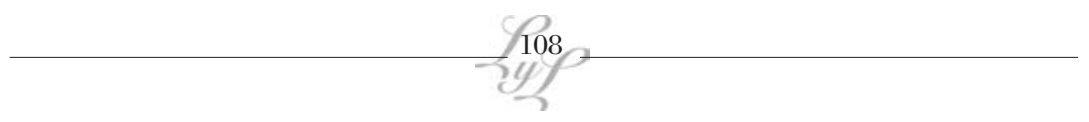


La voz que relata este proceso constata el viaje, donde la primera parte aborda la negación y la ira. El sujeto pasa a una nueva categorización, ahora es el 'enfermo' y este nuevo estatus genera una marginación del entorno y de lo cotidiano que lo aíslan en una vorágine de sensaciones incomunicables a los demás (a los no enfermos).

El hablante se presenta como quien ha sido invadido por un ente externo que no le pertenece: "Escríbele una carta al cangrejo y pregúntale al cabrón por qué eligió tu pulmón como si fuera un par de rocas" (Millán, 2007:19). El cangrejo es la representación del cáncer, debido a la connotación semántica que éste tiene con el signo del zodiaco Cáncer que es representado por este crustáceo. Al respecto, el animal ha decidido habitar entre las rocas (pulmones) del poeta sin previo aviso, y sin posibilidades de arrojarlo fuera.

En el transcurso donde el sujeto pasa a este nuevo estado, donde comienzan a habitarse otras significaciones, se viaja hacia el origen. Se retorna hacia el punto de partida como un mecanismo de buscar la trascendencia. Se quiere entender la muerte como un viaje hacia otro estadio y no una degradación: "Estoy dedicado al corte y la confección de una distancia/una mortaja, tejo el capullo de mi mudanza/ empiezo a tejer un secreto de mi próxima metamorfosis" (Millán, 2007:15). La muerte no es el final, sino un paso hacia otro estadio; la trascendencia busca en la muerte un volver a nacer, encarnado en la imagen del capullo o crisálida que luego de la metamorfosis da origen a una mariposa.

Este recorrido de significaciones se realiza a través de la escritura. Todo adquiere una nueva posibilidad y se hacen necesarios estos nuevos significados como una manera de resistir frente a la inminencia de la muerte que todo lo desmorona. Para Millán, la escritura es sobrevivencia: "Escribir Veneno de escorpión azul es hacer algo antes de morir, luchar por tu vida" (Millán, 2007:40). El sujeto se mantiene vivo a través de las palabras y el lenguaje, no es una sobrevivencia a la muerte en la posteridad, es una sobrevivencia presente, donde el lenguaje teje la realidad y le permite transformar la situación de acuerdo a los cambios que va sufriendo el sujeto.

En este sentido, el pilar de esta lucha por la vida, por la sobrevivencia, será la imagen del escorpión; puesto que aparecerá como una esperanza frente a la enfermedad. La única manera de poder derrotar al cangrejo es a través de la picada de este escorpión: "Pugna entre células activadas malignas descontroladas/ y el efecto letárgico del veneno del escorpión azul/Batallan en las vísceras esponjosas y negras y azules, /verdes, colo- 
radas, camisetas y banderas" (Millán, 2007:69). El veneno del escorpión se ve como aquella sustancia poderosa y terrible que puede aniquilar la enfermedad que no quiere abandonar el cuerpo. En el recorrido de la enfermedad, el veneno del escorpión se convertirá en un ritual, y la esperanza estará arraigada en cualquier acto mágico (remedios naturales) que pueda ayudar al sujeto a mejorar. El veneno del escorpión es el nombre que el autor le da a su propia batalla corporal.

La enfermedad se resiste a abandonar el cuerpo, se arraiga en el sujeto sin poder extirparla; incluso llevándolo a considerar el cuerpo como un basurero, como un lugar de los desechos. La enfermedad se incrusta en el cuerpo de manera determinante: "El cáncer es una verruga interna y gigante que crece en secreto dentro de uno" (Millán, 2007:91). Asimismo, la muerte aparece como una semilla que no se puede extirpar, la muerte es algo que crece dentro del sujeto y se asimila con un embarazo monstruoso, lo que crece no es vida, sino enfermedad y muerte:

Sangro como una mujer

Sin embargo, los pulmones

son el útero del monstruo.

Los embarazados pulmones

son el botón de un monstruo obtuso. (Millán, 2007:209).

La enfermedad hace perder el control del sujeto sobre su propio cuerpo, va modificando su estructura, su metabolismo, su rutina cotidiana, sus percepciones; el ritmo natural se pierde y el sujeto debe adaptarse a un ritmo ajeno que es la propia enfermedad. En este sentido, tal como mencionábamos anteriormente, el sujeto escribe como una manera de sobrevivir, como un mecanismo de adaptación. Este mecanismo es la escritura. El lenguaje es, para la voz poética, una forma de recuperar el control sobre el cuerpo.

Tal como en el caso de Lihn, la dimensión corporal se presenta como un cuerpo textual; pero, en este sentido, como una posibilidad de ampliación del cuerpo del cual se ha perdido el control.

De esta manera, el límite primero del cuerpo es la boca: "dibujan una boca abierta y parlante/ frente a mi boca callada para oír" (Millán, 2007:105). Frente a la muerte que se avecina, todo aparece con un sentido renovado, todo genera el imperativo de una nueva mirada. La boca es el lugar del cuerpo que encarna la conciencia del sujeto y que genera su voz; hay que precisar, además, que la voz corporal se va perdiendo a medida que transcurre el relato de la enfermedad.

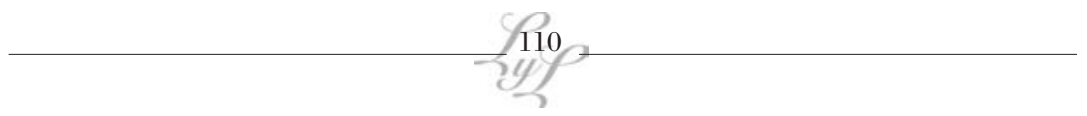


Las palabras adquieren una nueva precisión. El poeta se sintoniza con la palabra y la percepción de un modo integrador. Esta reunión de palabra y percepción son parte de la creación de este cuerpo textual como una extensión, habitable para el poeta, a través de la palabra: "La proximidad de la muerte nos afina. Conseguimos una vibración común y central. [...] A medida que el tiempo se agota/vivo cada vez más en la lengua" (Millán, 2007:146).

El autor se convierte en sus propias palabras. Se abandona el cuerpo enfermo, ya no hay pertenencia sobre ese cuerpo. El cuerpo enfermo se comparte con los otros, con los amigos, la familia, las revistas; el sujeto deja de ser y se convierte en ese cuerpo enfermo para los demás. La respuesta que encuentra Millán es habitar en su propia escritura. Su cuerpo se convierte en la escritura misma:

Me siento en la escalera de incendio y escribo como si saliera a trotar por un rato por el parque cercano. Cuesta remontar la juerga al principio, pero luego las palabras piernas se mueven y corren por las páginas de la libreta. (Millán, 2007:291).

La liberación se hace posible a través de la dimensión textual, este acto de sobrevivencia también es un acto de rescate; ya que permite al sujeto habitar su corporalidad a través de la palabra, dejando fuera la enfermedad. En este sentido, la escritura es también la posibilidad de habitar fuera del cuerpo agónico. La enfermedad y el camino de su padecimiento conllevan también a la oportunidad de resignificarse textual y corporalmente y, en esta acción, obtener la liberación a través de la palabra.

\section{Conclusiones}

El análisis realizado nos permite concluir que cada autor posee una aproximación particular al problema de la agonía del cuerpo enfermo y las representaciones de la muerte asociadas a él. El carácter testimonial de los textos revela una mutación del hablante en el proceso que conduce hacia un final irreversible; llevando al sujeto a renovar y cuestionar las significaciones de su propia realidad.

En Poemas renales, de Jorge Torres, la escritura tiene un valor protector sobre el sujeto; se utiliza como una pantalla de resguardo frente a la vivencia de la enfermedad. Esta instancia mediadora, la palabra, le permite al sujeto no padecer el dolor de manera directa. Es por ello que la aceptación de la muerte solo puede generarse a través de una dimensión conflictiva con lo trascendente. 
En Diario de muerte, de Enrique Lihn, la creación poética es un mandato. Se escribe por necesidad, se genera la obligación de poner el sufrimiento en palabras. Este hecho, permite que el hablante pueda regular la intensidad de su padecimiento; poniendo un control al caos que supone la muerte. La única forma de experimentar el fin de la vida es a través de la escritura.

En Veneno de escorpión azul de Gonzalo Millán el acto de escribir es una manera de sobrevivir. Mientras se construya el relato, el sujeto logra la pervivencia, puesto que su dimensión física va en deterioro. Es por ello que el sujeto corporal se convierte en el sujeto textual, como una posibilidad de vivir a través de las propias palabras.

En conclusión, podemos afirmar que, en estos tres poetas, la poesía no es sólo una herramienta para enfrentar el padecimiento, sino que la palabra permite bordear la mudez o zona muda, que es la enfermedad. Mediante la metáfora, la muerte se muda en un nuevo lenguaje del cuerpo, que regula y dosifica el sufrimiento corporal, resignificando el dolor. Esta resignificación que se corresponde en el texto poético con un proceso de duelo ante la experiencia de cercanía de la muerte consiste en volver a nombrar el deterioro del cuerpo, esta vez, mediante la poesía. En las imágenes del cuerpo agónico, el sujeto transgrede el límite de la muerte o del fin de la vida y logra en la palabra un alivio para la herida del yo.

\section{Referencias Bibliográficas}

Foucault, M. (1999). Prefacio a la transgresión. Entre filosofía y literatura (pp. 163 -180). Barcelona: Paidós.

Freud, S. (1999). Lo ominoso. Obras Completas. Buenos Aires: Amorrortu. 219-251.

(1999). Tótem y tabú. Obras Completas. Buenos Aires: Amorrortu. 7-162.

Gómez de Silva, G. (2006). Breve diccionario etimológico de la lengua española. Ciudad de México: Fondo de Cultura Económica ediciones.

Kristeva, J. (1994). De la identificación: Freud, Baudelaire, Stendhal. (El) trabajo de la metáfora. Barcelona: Gedisa. 43-71.

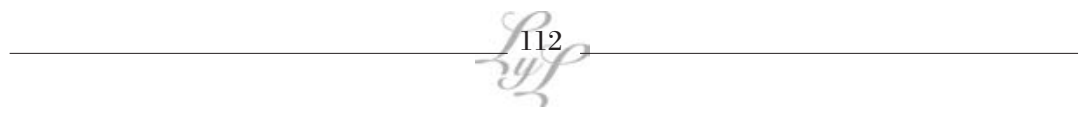


(1997). Sol negro. Depresión y melancolía. Caracas: Latinoamericana. Lihn, E. (1989). Diario de muerte. Santiago: Universitaria.

Mansilla, S. (1994). En libre plática. Valdivia: Barba de Palo.

Millán, G. (2007). Veneno de escorpión azul. Santiago: Universidad Diego Portales.

Sontag, S. (1996). La enfermedad y sus metáforas y el sida y sus metáforas. Madrid: Taurus.

Torres, J. (1992). Poemas renales. Valdivia: El Kultrún/ Barba de Palo. 